\title{
Mathematical model of filtration under conditions of variable porosity taking into account biocolmatage
}

https://doi.org/10.31713/MCIT.2020.36

\author{
Martyniuk Petro Mykolayovych \\ Department of Computer Science and Applied Mathematics \\ The National University of Water and Environmental \\ Engineering \\ Rivne, Ukraine \\ p.m.martyniuk@nuwm.edu.ua
}

\author{
Michuta Olga Romanivna \\ Department of Computer Science and Applied Mathematics \\ The National University of Water and Environmental \\ Engineering \\ Rivne, Ukraine \\ o.r.michuta@nuwm.edu.ua
}

\author{
Ivanchuk Natalia Vitaliivna \\ Department of Computer Science and Applied Mathematics \\ The National University of Water and Environmental Engineering \\ Rivne, Ukraine \\ n.v.medvid@nuwm.edu.ua
}

\begin{abstract}
The authors' research concerns the equations of filtration in soils taking into account the growth of microorganisms. A review of works, statement of research problems and a mathematical model of filtration of an organic substances solution, taking into account the effect of biocolmatage was conducted (Abstract)
\end{abstract} words)

Keywords_filtering; biocolmatage; mathematical model (key

\section{INTRODUCTION}

In [1-5] the processes of filtration, moisture transfer, compaction in soils in case of exposure to inorganic chemicals were studied by methods of mathematical and computer modelling. From the point of view of practically important problems the specified processes concern pollution of environment by industrial productions waste. However, no less significant influence on the processes in porous media can have organic matter. The source of such pollution can be household waste storage facilities. When organic matter enters the soil, one of the factors influencing the change in the hydrological parameters of the porous medium is the development of microorganisms and, as a consequence, the change in the porosity of the medium itself. This is evidenced by the following review of scientific papers on the impact of increasing the biomass of microorganisms on the filtration parameters of soils. The development of microorganisms leads to a decrease in the effective porosity of the medium, which is manifested in the phenomenon of biocolmatage.

In [6] there are presented the results of field experiments on the study of the influence of biocolmatage on the hydraulic conductivity of sandy soil. The author provides a thorough analysis of the known dependences of the filtration coefficient on the change in porosity as a result of microbial activity.
In [7], the influence of microbial development on the filtration coefficient of a mixture of silt and bentonite was investigated (three samples with a bentonite content of $0 \%$, $5 \%, 10 \%$ were studied). In the study of nutrient solution filtration on the 540th day from the beginning of the study, the filtration coefficient of all soil samples decreased by almost an order of magnitude. If the researchers then changed the nutrients to antibiotics and antifungal, then on the 720th day (180 days after the change) the filtration rate acquired values typical of the beginning of the experiment. In [8], field experiments showed that the value of the filtration coefficient of soil samples decreases by an order of magnitude 12 days after the start of tests for the filtration of organic matter.

In [9], the authors conducted a theoretical assessment of the effect of the presence of biomass in a porous medium on the change in permeability (in the sense of liquid filtration) of this medium. In particular, received

$$
\frac{\overline{\mathrm{k}}_{\mathrm{b}}}{\overline{\mathrm{k}}_{0}}=\left(1-\frac{\mathrm{n}^{\mathrm{f}}}{\mathrm{n}_{0}}\right)^{19 / 6}
$$

where $\overline{\mathrm{k}_{0}}, \overline{\mathrm{k}_{\mathrm{b}}}$ - permeability coefficients of the "pure" porous medium and the environment under the influence of microbial activity; $\mathrm{n}^{\mathrm{f}}$ is the volume fraction of the biomass; $\mathrm{n}_{0}$ is the soil porosity. The mathematical model of dynamics of microorganisms in the porous environment offered by authors includes three basic equations: 1) the differential equation of nutrient distribution; 2) the differential equation of distribution and development of microbes in the pore fluid; 3) differential equation that describes the dynamics of changes in the number of microorganisms adsorbed by the skeleton of the porous medium. 


\section{Modeling, control and information technologies -2020}

\section{MATHEMATICAL MODELS OF BiOMASS DyNAMICS IN A POROUS ENVIRONMENT (REVIEW)}

To mathematically describe the effect of biocolmatage, first of all, there is a need to develop mathematical and computer models of the microorganism dynamics in a porous environment.

Article [10] is a thorough review work, which focuses on models of development of microorganisms in the general biogeochemical dynamics (the paper contains more than 320 scientific sources from this area of research). The authors note that historically the first model of the dynamics of microorganisms was a model according to the Monod's equation of growth of microorganisms

$$
\frac{\mathrm{dB}}{\mathrm{dt}}=\mu \mathrm{B}=\mu_{\max } \mathrm{B} \frac{\mathrm{S}}{\mathrm{k}_{\mathrm{S}}+\mathrm{S}},
$$

where, according to the author's designations and definitions, $\mathrm{B}$ is the biomass, $\mu_{\max }$ is the maximum specific growth rate, $S$ is the concentration of the substrate, and $\mathrm{k}_{\mathrm{S}}$ is the Monod halfsaturation constant, that is, the substrate concentration when $\mu=0.5 \mu_{\max }$. There are many modifications in this point model, which include the presence of several types of microorganisms, their interaction, the presence of biochemical reactions and so on. Models of this type do not take into account the mobility of microorganisms, one of the reasons is the movement of groundwater or chemical solutions. Therefore, other types of models of bio-geodynamics are those based on the equation of the parabolic type (analogous to the diffusion-convection equations). This is also noted in [11], which provides an overview of mathematical models of the dynamics of changes in the number of microorganisms. In retrospect, the first were models based on ordinary differential equations, and in recent decades such models have been described by differential equations in second-order partial derivatives and their systems.

In [12] it is proposed to improve the mathematical model of the spread and development of bacteria in porous media by taking into account the phenomenon of adsorption of microorganisms by the solid skeleton of the porous medium. This effect is taken into account in the one-dimensional equation of bacterial transfer

$$
\begin{gathered}
\varepsilon \frac{\partial \mathrm{c}_{\mathrm{b}}}{\partial \mathrm{t}}= \\
=\mathrm{D}_{\mathrm{b}^{\varepsilon}} \frac{\partial^{2} \mathrm{c}_{\mathrm{b}}}{\partial \mathrm{x}^{2}}-\left(\mathrm{V}_{\mathrm{p}}+\mathrm{V}_{\mathrm{g}}+\mathrm{V}_{\mathrm{c}}\right) \varepsilon \frac{\partial \mathrm{c}_{\mathrm{b}}}{\partial \mathrm{x}}+\left(\mathrm{r}_{\mathrm{r}}-\mathrm{r}_{\mathrm{c}}\right)+\left(\mathrm{r}_{\mathrm{gf}}-\mathrm{r}_{\mathrm{df}}\right),
\end{gathered}
$$

where (according to the author's designations):

$\mathrm{c}_{\mathrm{b}}$ is the concentration of bacterial cells in the suspension $\left(\mathrm{kg} / \mathrm{m}^{3}\right) ; \varepsilon$ - porosity; $\mathrm{D}_{\mathrm{b}}$ - dispersion coefficient for bacterial cells $\left(\mathrm{m}^{2} / \mathrm{s}\right) ; \mathrm{v}_{\mathrm{p}}$ - pore water velocity $(\mathrm{m} / \mathrm{s}) ; \mathrm{v}_{\mathrm{g}}$ - the sedimentation rate of bacteria $(\mathrm{m} / \mathrm{s}) ; \mathrm{v}_{\mathrm{c}}$ - chemotactic rate of bacteria $(\mathrm{m} / \mathrm{s}) ; r_{r}$ - the rate of release of captured cells $\left(\mathrm{kg} / \mathrm{m}^{3} \mathrm{~s}\right) ; r_{\mathrm{c}}$ - the rate of capture of suspended cells $\left(\mathrm{kg} / \mathrm{m}^{3} \mathrm{~s}\right)$; $r_{\text {gf }}$ - the growth rate of freely suspended cells $\left(\mathrm{kg} / \mathrm{m}^{3} \mathrm{~s}\right)$;

$r_{d f}$ - the rate of decay of freely suspended cells $\left(\mathrm{kg} / \mathrm{m}^{3} \mathrm{~s}\right)$.

Article [13] contains a broad overview of scientific sources on this topic, theoretical generalizations and the results of field experiments. The focus is on the phenomenon of biocolmatage, which is caused by the development of microbial biomass in a porous medium. The author identifies two types of biomass: $\mathrm{X}_{\mathrm{w}}$ - suspended biomass (biomass of microorganisms in the pore fluid) (expressed as biomass per unit volume of pore water); $\mathrm{X}_{\mathrm{f}}$ - concentration of adsorbed biomass (expressed as biomass per unit matrix mass). Change of $X_{w}$ is described by the convection-diffusion equation

$$
\begin{gathered}
\frac{\partial \mathrm{X}_{\mathrm{W}}}{\partial \mathrm{t}}= \\
=\nabla \cdot\left(\mathbf{D} \nabla \mathrm{X}_{\mathrm{W}}\right)-\nabla \cdot\left(\mathbf{u} \mathrm{X}_{\mathrm{W}}\right)+\mathrm{r}_{\mathrm{W}}^{\text {growth }}-\mathrm{r}_{\mathrm{W}}^{\mathrm{dec}}-\mathrm{r}^{\mathrm{det}} \mathrm{k}+\mathrm{r}^{\mathrm{att}},
\end{gathered}
$$

where $\mathrm{D}$ - dispersion tensor; $\mathrm{k}$ - is the exchange rate between the concentration of adsorbed and suspended biomass; $r{ }^{\text {growth }}$ is the growth rate; $r^{\text {dec }}$ - rate of extinction (decay). Members $\mathrm{r}^{\text {growth }}$ and $\mathrm{r}^{\mathrm{dec}}$ depend on the supply of nutrients and other conditions of the system. Also $r^{\text {dec }}$ - sticking speed and $\mathrm{r}^{\mathrm{dec}}=\mathrm{k}_{\mathrm{det}} \mathrm{X}_{\mathrm{f}}, \mathrm{k}_{\mathrm{det}}$ - as the coefficient of separation rate; $\mathrm{r}^{\text {att }}$ sticking speed. To determine this indicator, the authors [13] note two dependencies in the scientific literature

$$
\mathrm{r}^{\mathrm{att}}=\mathrm{k}_{\mathrm{att}} \mathrm{X}_{\mathrm{W}},
$$

where $\mathrm{k}_{\mathrm{att}}$ the rate coefficient determined from filtration theory;

$$
\mathrm{r}^{\mathrm{att}}=\left(\mathrm{c}_{1} \mathrm{n}_{\mathrm{f}}+\mathrm{c}_{2}\right) \mathrm{nX}_{\mathrm{W}},
$$

where $\mathrm{n}$ average porosity, $\mathrm{n}_{\mathrm{f}}$ volume fraction of biomass, and $\mathrm{c}_{1}$ and $\mathrm{c}_{2}$ parameters for calibration. It is proposed to describe the dynamics of changes in the concentration of microorganisms adsorbed by the skeleton of the porous medium by the equation

$$
\frac{\partial X_{f}}{\partial t}=r_{f}^{\text {growth }}-r_{f}^{\text {dec }}-r^{\text {det }}+r^{\text {att }} \frac{1}{k} \text {. }
$$

Similarly to the equation for $\mathrm{X}_{\mathrm{w}}$, the indices "growth" and "dec" above mean birth and death.

\section{FILTRATION EQUATIONS TAKING INTO ACCOUNT THE EFFECT OF BIO-COLMATAGE}

The ideas of deriving the equations of filtration and moisture transfer in the case of variable porosity are presented in $[1-3,5]$. Also in [5] these ideas are used to derive a modified 


\section{Modeling, control and information technologies -2020}

kinematic condition on a moving free surface in the study of filtration processes in the body of the soil dam. The idea is to write the continuity equations for the components of the porous medium through complete derivatives in time and to apply the rules for calculating the derivatives of the composite functions. We apply this approach in order to take into account the influence of the dynamics of microorganisms and biocolmatage processes on filtration processes in a porous medium.

In the porous area, select a rectangular parallelepiped with a total volume $\mathrm{V}$ with sides $\mathrm{dx}, \mathrm{dy}, \mathrm{dz}$, parallel to the coordinate axes. Then, using the known approach, we obtain the equation of continuity for the pore fluid

$$
\frac{\mathrm{d}}{\mathrm{dt}}(\rho \sigma \mathrm{V})+\nabla \cdot(\rho \mathbf{u}) \mathrm{V}=0
$$

where $\sigma$-porosity, $\rho$ - density of pore fluid, $\mathbf{u}$ - filtration rate. Assume that impurities of organic substances in the pore liquid are insignificant and their effect on the density $\rho$ can be neglected. Also, for now, consider the case of a nondeformable porous medium. That is, the value of the allocated volume $\mathrm{V}$ is constant over time. Then from the continuity equation we have

$$
\frac{\mathrm{d} \sigma}{\mathrm{dt}}+\nabla \cdot \mathbf{u}=0
$$

The change in porosity $\sigma(\mathbf{X}, t)$ is due to a change in the concentration of microorganisms, both adsorbed by the skeleton of the porous medium and present in the pore fluid $\mathrm{B}_{\mathrm{s}}(\mathbf{X}, \mathrm{t})$ and $\mathrm{B}_{\mathrm{w}}(\mathbf{X}, \mathrm{t})$. Here $\mathbf{X}=(\mathrm{x}, \mathrm{y}, \mathrm{z}), \mathrm{t}-\mathrm{time}$. Then

$$
\sigma(\mathbf{X}, \mathrm{t})=\sigma_{0}(\mathbf{X})-\sigma_{\mathrm{B}}\left(\mathrm{B}_{\mathrm{S}}, \mathrm{B}_{\mathrm{W}}\right),
$$

where $\sigma_{0}(\mathbf{X})$ - porosity of the "skeleton" of the porous medium (porosity in the complete absence of microorganisms), $\sigma_{B}\left(B_{s}, B_{w}\right)$ - biovolume (reduced to the unit volume of the porous medium), which depends on the biomass of microorganisms in the porous medium. We believe that in the porous medium there are the same type of microorganisms, as well as the same type of chemical solution. Note that determining the interdependence of biovolume and biomass is not a trivial task $[14,15]$.

Then

$$
\begin{gathered}
\frac{\mathrm{d} \sigma}{\mathrm{dt}}=\frac{\mathrm{d}}{\mathrm{dt}}\left(\sigma_{0}(\mathbf{X})-\sigma_{\mathrm{B}}\left(\mathrm{B}_{\mathrm{S}}, \mathrm{B}_{\mathrm{W}}\right)\right)=-\frac{\mathrm{d} \sigma_{\mathrm{B}}\left(\mathrm{B}_{\mathrm{S}}, \mathrm{B}_{\mathrm{W}}\right)}{\mathrm{dt}} \\
=-\frac{\partial \sigma_{\mathrm{B}}}{\partial \mathrm{B}_{\mathrm{S}}} \cdot \frac{\partial \mathrm{B}_{\mathrm{S}}}{\partial \mathrm{t}}-\frac{\partial \sigma_{\mathrm{B}}}{\partial \mathrm{B}_{\mathrm{W}}} \cdot \frac{\partial \mathrm{B}_{\mathrm{W}}}{\partial \mathrm{t}} .
\end{gathered}
$$

Let's continue according to Darcy's law

$$
\mathbf{u}=-\mathbf{K}_{\mathbf{h}}(\sigma) \nabla \mathbf{h}
$$

from (1) we have the filtration equation

$$
-\frac{\partial \sigma_{\mathrm{B}}}{\partial \mathrm{B}_{\mathrm{s}}} \cdot \frac{\partial \mathrm{B}_{\mathrm{s}}}{\partial \mathrm{t}}-\frac{\partial \sigma_{\mathrm{B}}}{\partial \mathrm{B}_{\mathrm{W}}} \cdot \frac{\partial \mathrm{B}_{\mathrm{W}}}{\partial \mathrm{t}}=\nabla \cdot\left(\mathbf{K}_{\mathbf{h}}(\sigma) \nabla \mathrm{h}\right),
$$

where $\mathbf{K}_{\mathbf{h}}(\sigma)$ - rate (tensor) filtering, which depends on the porosity and therefore - biomass of microorganisms in porous media [10], the process also takes into account biokolmatage; h - head.

\section{EQUATION OF CHANGE OF CONCENTRATION OF ORGANIC SUBSTANCE IN PORE WATER}

The equation of mass transfer in the liquid component is obtained from the equation of continuity for the concentration $\mathrm{c}$ of organic matter, taking into account the derivative of the composite function and the above assumptions about the density $\rho$

$$
\frac{\mathrm{d}(\sigma \mathrm{c})}{\mathrm{dt}}+\nabla \cdot \mathbf{q}_{\mathbf{c}}=\mathrm{r}
$$

where

$$
\mathbf{q}_{\mathbf{c}}=-\mathbf{D}_{\mathbf{c}} \nabla \mathbf{c}+\mathbf{c u}
$$

$\mathbf{D}_{\mathbf{c}}$ - is the coefficient (tensor) of the coefficients of convective diffusion of organic matter in a porous medium, $r$ - is the function of chemical sources and effluents. Then from (2) we obtain

$$
\sigma \frac{\partial \mathrm{c}}{\partial \mathrm{t}}=\nabla \cdot\left(\mathbf{D}_{\mathbf{c}} \nabla \mathrm{c}\right)-\mathbf{u} \nabla \mathrm{c}-\mathrm{c}\left(\frac{\mathrm{d} \sigma}{\mathrm{dt}}+\nabla \cdot \mathbf{u}\right)+\mathrm{r} .
$$

Next from (3), taking into account (1), we obtain the final form of the equation

$$
\sigma \frac{\partial \mathrm{c}}{\partial \mathrm{t}}=\nabla \quad\left(\mathrm{D}_{\mathrm{c}} \nabla \mathrm{c}\right) \quad \mathrm{u} \nabla \mathrm{c}+\mathrm{r} .
$$

The development of microorganisms occurs due to the presence of dissolved organic substances in the pore water. Therefore, in case of biomass consumption of nutrients we have

$$
\mathrm{r}=-\frac{1}{\mathrm{Y}}\left(\frac{\partial \mathrm{B}_{\mathrm{w}}}{\partial \mathrm{t}}+\frac{\partial \mathrm{B}_{\mathrm{f}}}{\partial \mathrm{t}}\right)
$$

where $\mathrm{Y}$ is the bacterial yield.

\section{MATHEMATICAL MODEL}

Assume that the filtration is investigated in the region $\Omega$ with boundary $\Gamma$. The mathematical model of the studied interconnected processes in the soil will contain: 1) the filtration equation; 2) the equation of change of concentration of organic substances in pore water; 3 ) the equation of the dynamics of microorganisms in the pore fluid; 4) the equation 


\section{Modeling, control and information technologies -2020}

of the dynamics of microorganisms adsorbed by the skeleton of the porous medium. In addition, the mathematical model should be supplemented by the known dependences of the filtration coefficient on the biovolume, as well as the function of the interdependence of biovolume and biomass. Then according to the above calculations we have the following mathematical model:

$$
\begin{aligned}
& -\frac{\partial \sigma_{\mathrm{B}}}{\partial \mathrm{B}_{\mathrm{s}}} \cdot \frac{\partial \mathrm{B}_{\mathrm{s}}}{\partial \mathrm{t}}-\frac{\partial \sigma_{\mathrm{B}}}{\partial \mathrm{B}_{\mathrm{W}}} \cdot \frac{\partial \mathrm{B}_{\mathrm{W}}}{\partial \mathrm{t}}=\nabla \cdot\left(\mathbf{K}_{\mathbf{h}}(\sigma) \nabla \mathrm{h}\right), \\
& \sigma \frac{\partial \mathrm{c}}{\partial \mathrm{t}}=\nabla \cdot\left(\mathbf{D}_{\mathbf{c}} \nabla \mathrm{c}\right)-\mathbf{u} \nabla \mathrm{c}+\mathrm{r}, \\
& \frac{\partial \mathrm{X}_{\mathrm{W}}}{\partial \mathrm{t}}= \\
& =\nabla \cdot\left(\mathbf{D} \nabla \mathrm{X}_{\mathrm{W}}\right)-\nabla \cdot\left(\mathbf{u} \mathrm{X}_{\mathrm{W}}\right)+\mathrm{r}_{\mathrm{W}}^{\text {growth }}-\mathrm{r}_{\mathrm{W}}^{\mathrm{dec}}-\mathrm{r}^{\mathrm{det}} \mathrm{k}+\mathrm{r}^{\mathrm{att}} \text {, } \\
& \frac{\partial \mathrm{X}_{\mathrm{f}}}{\partial \mathrm{t}}=\mathrm{r}_{\mathrm{f}}^{\text {growth }}-\mathrm{r}_{\mathrm{f}}^{\mathrm{dec}}-\mathrm{r}^{\mathrm{det}}+\mathrm{r}^{\text {att }} \frac{1}{\mathrm{k}}, \\
& \mathbf{u}=\mathbf{K}_{\mathbf{h}}(\sigma) \nabla \mathbf{h} \\
& \left.\mathrm{l}_{1} \mathrm{~h}(\mathrm{X}, \mathrm{t})\right|_{\Gamma_{\mathrm{t}_{0}}}=\mathrm{H}_{1}(\mathrm{X}, \mathrm{t}),\left.\mathrm{l}_{2} \mathrm{c}(\mathrm{X}, \mathrm{t})\right|_{\Gamma_{\mathrm{t}_{0}}}=\mathrm{C}_{1}(\mathrm{X}, \mathrm{t}), \\
& \left.\mathrm{l}_{3} \mathrm{X} \mathrm{W}_{\mathrm{W}}(\mathrm{X}, \mathrm{t})\right|_{\Gamma_{\mathrm{t}_{0}}}=\mathrm{X}_{\mathrm{W}}(\mathrm{X}, \mathrm{t}),(\mathrm{X}, \mathrm{t}) \in \Gamma_{\mathrm{t}_{0}}, \\
& \mathrm{c}(\mathrm{X}, 0)=\mathrm{C}_{0}(\mathbf{X}), \mathrm{X}_{\mathrm{W}}(\mathrm{X}, 0)=\mathrm{Xw}_{0}(\mathrm{X}), \mathrm{X}_{\mathrm{f}}(\mathrm{X}, 0)=\mathrm{X}_{\mathrm{f}_{0}}(\mathrm{X}), \\
& \mathrm{X} \in \bar{\Omega} \text {, }
\end{aligned}
$$

where $l_{1}, l_{2}, l_{3}$ - operators that set the boundary conditions for the pressure, concentration of organic matter and biomass of microorganisms in the pore fluid of the porous medium on the side surface $\Gamma_{\mathrm{t}_{0}}$ of the cylinder $\mathrm{Q}_{\mathrm{t}_{0}}=\Omega \times\left(0 ; \mathrm{t}_{0}\right]$.

\section{CONCLUSIONS AND DIRECTIONS OF FURTHER RESEARCH}

The filtration equation is derived in the work, which allows to systematically take into account the influence of the development of microorganisms on the process of pressure change in the pore fluid. From the point of view of the equations of mathematical physics, the equation is quasistationary, which does not contain derivatives of pressure over time, but contains such derivatives from the biomass of microorganisms. Also, the filtration coefficient significantly depends on the porosity, and hence on the biocolmatage of the pore space of the medium. The corresponding mathematical model is formed. Further research requires the actual study of the significance of the influence of the considered factors on the filtration process. Since the mathematical model is nonlinear, it is necessary to use numerical methods of mathematical physics. But in fact the ultimate goal of research is how it will affect the spread of contaminants in soils, as well as the dynamics and efficiency of water treatment in bioplate filters [4]. These questions remain open and will be the essence of the following scientific works of the authors.

\section{REFERENCES}

[1] T. V. Kutya, V. A. Gerus, P. M. Martynyuk, "Modeling of the Moisture Transfer in Soils with Regard for Thermal and Chemical Factors," Journal of Mathematical Sciences, vol. 240, issue 2, 2019, pp. $208-$ 219.

[2] P. M. Martyniuk, T. V. Kutia, O. P. Ostapchuk, O. L.Pinchuk, "Filtration equation and movement of the wetting interface in case of pressure pipeline breakthrough under the conditions of variable porosity," Journal of Heat and Mass Transfer, vol. 15, issue 2, 2018, pp. $281-293$.

[3] V. A. Herus, N. V. Ivanchuk, P. M. Martyniuk, "A System Approach to Mathematical and Computer Modeling of Geomigration Processes Using Freefem++ and Parallelization of Computations," Cybernetics and Systems Analysis, vol. 54, no. 2, 2018, pp. 284-294.

[4] V. Moshynskyi, V. Filipchuk, N. Ivanchuk, P. Martyniuk, "Computer modeling of water cleaning in wetland taking into account of suffosion ang colmatation," Eastern-European Journal of Enterprise Technologies, №1/10 (91), 2018, pp. 38-43.

[5] N. V. Medvid, V. A. Herus, P. M. Martyniuk, "Modification of Kinematic Boundary Condition at Free Surfaces in Filtration Problems by means of Earth Dam," BulletinofTaras Shevchenko National University of Kyiv. Series: Physics\&Mathematics, vol. 1, 2016, pp. 119-124.

[6] K. Seki, "Biological Clogging of Sand Columns, " Open Journal of Soil Science, vol. 3, 2013, pp. 148-152.

[7] D. A. Glatstein , F. M.Francisca, "Hydraulic conductivity of compacted soils controlled by microbial activity. Environmental Technology," vol. 35 , iss. 15, 2014, pp. 1886-1892.

[8] Q.Tang, F.Gu, Yu Zhang, Y.Zhang, J.Mo, "Impact of biological clogging on the barrier performance of landfill liners," Journal of Environmental Management, vol. 222, 2018, pp. 44-53.

[9] T. P. Clement, B. S. Hooker, R. S. Skeen, "Macroscopic Models for Predicting Changes in Saturated Porous Media Properties Caused by Microbial Growth,” Ground Water, vol. 34, №5, 1996, pp. 934-942.

[10] M. Thullner, P. Regnier, "Microbial Controls on the Biogeochemical Dynamics in the Subsurface," Reviews in Mineralogy and Geochemistry, vol. 85, 2019, pp. 265-302.

[11] A. Succurro, O. Ebenhoh, "Review and perspective on mathematical modeling of microbial ecosystems," Biochemical SocietyTransactions, vol. 46(2), 2018, pp. 403-412.

[12] T. K. Sen, D. Das, K. C. Khilar, G. K. Suraishkumar, "Bacterial transport in porous media: New aspects of the mathematical model," Colloidsand Surfaces A: Physico chemical and Engineering Aspects, vol. 260, iss. 1-3, 2005, pp. 53-62.

[13] M. Thullner, "Comparison of bioclogging effects in saturated porous media within one- ad two-dimensional flow systems," Ecological Engineering, vol. 36, 2010, pp. 176-196.

[14] J. A. van Veen, E. A. Paul, "Conversion of biovolume measurements of soil organisms, grown under various moisture tensions, to biomass and their nutrient content," Applied and environmental microbiology, vol. 34, no. 4, 1979, pp. 686-692.

[15] Gunnar Bratbak, "Bacterial biovolume and biomass estimations," Applied and environmental microbiology, vol. 49, no. 6, 1985, pp. 14881493. 